\title{
MONITORING ICE CRYSTALS CLOUDS: INVESTIGATION OF THE LIDAR DEPOLARIZATION RATIOS
}

\author{
Kalliopi - Artemis Voudouri ${ }^{1^{*}}$, Elina Giannakaki ${ }^{3,4}$, Mika Komppula ${ }^{3}$, Anna Gialitaki ${ }^{5}$, Athanasios \\ Natsis ${ }^{1}$ and Dimitris Balis ${ }^{1}$. \\ ${ }^{1}$ Laboratory of Atmospheric Physics, Physics Department, Aristotle University of Thessaloniki, \\ Greece \\ ${ }^{3}$ Finnish Meteorological Institute, P.O.Box 1627, FI-70211, Kuopio, Finland \\ ${ }^{4}$ Department of Environmental Physics and Meteorology, Faculty of Physics, University of Athens, \\ Greece \\ ${ }^{5}$ National Observatory of Athens, NOA, Institute for Astronomy, Astrophysics, Space Applications \\ and Remote Sensing, Greece
}

*Email: kavoudou@physics.auth.gr

\begin{abstract}
A cirrus cloud dataset from a groundbased lidar in a sub-arctic station is analyzed in terms of the particle depolarization ratio. The depolarization values $-\delta$ - showed a broad distribution, ranging between 0.25 and 0.7 , with a mean value of $0.38 \pm$ 0.07 . This variability is examined in correlation with temperature dependencies and the cirrus optical depth. Depolarization values greater than 0.45 are observed from temperatures between $-60^{\circ} \mathrm{C}$ and $-40^{\circ} \mathrm{C}$, where horizontally oriented planar ice crystals are to be expected. Two case studies are also, discussed and analyzed in terms of depolarization height dependence.
\end{abstract}

\section{INTRODUCTION}

Cirrus clouds are present all seasons globally with a mean global coverage of about $20-30 \%$ in both hemispheres. This type of clouds are composed almost exclusively of nonspherical ice crystals and the crystal shape is found to be a hexagonal column/plate [1]. As the meteorological conditions and the evolution processes differ in different parts, a broad diversity of macrophysical properties of cirrus layers, is reported, given that ice particles can vary in size and number, crystal shapes, and orientation. Indeed, cirrus layers can be found in a large variety of shapes and sizes [2]. A quantity representative of the particle shape, the lidar depolarization ratio, can be regarded as an indicator of the shape of particles in the probed cirrus layer. Higher depolarization ratios are linked to higher shape ratios (columns) and low depolarization ratios to lower shape ratios (plates), according to literature [1]. Thus, differences in the measured depolarization ratio values can be linked to different ice crystals shape.

Given that, classification of cirrus clouds has important cloud microphysical and radiative consequences, their parameterization in circulation models, require a detailed understanding of their microphysical properties [3]. As it is still unclear how these properties drive ice cloud radiative properties, the variations of shape inside the cirrus layers could lead to important influence on the cloud radiative properties.

The high sensitivity of the lidar instrument to optically thin clouds makes it one of the instruments best suited to the study of ice clouds, especially when equipped to monitor the state of light polarization.

In this study, a dataset of depolarization values of cirrus layers monitored by a ground-based lidar is analyzed. Measurements were performed in a specific environment in continental Finland. The variability of the measured depolarization values with height, cloud optical depth, temperature, etc., is analyzed.

\section{METHODOLOGY}

\subsection{Data and Methodology}


Data set from a ground-based multi-wavelengthpolarization-Raman lidar (Polly ${ }^{\mathrm{XT}}$ ) system is analyzed in this study. The system was automatically and continuously operational 24/7providing observations of clouds and aerosol particles in Kuopio $\left(62.74^{\circ} \mathrm{N}, 27.54^{\circ} \mathrm{E}, 190 \mathrm{~m}\right.$ a.s.l) Finland during period 2012-2016. Detailed description of the system, can be found [4] and observations can be found online at http://polly.tropos.de.

The detection of the cirrus geometrical boundaries was made by applying an automatic algorithm to the lidar measurements. The method was based on a wavelet covariance transform (WCT), a method that detects discontinuities in lidar signal profile, such as the cloud boundaries [5]. The recognised loud layers were classified as cirrus layers only when the following criteria were met: i) the depolarization value was higher than 0.25 , ii) the altitude of the layers was higher than $7 \mathrm{~km}$ and iii) the temperature base was below $-27^{\circ} \mathrm{C}$.

The depolarization ratio is computed by using the the cross signal of the 532nm channel and the total signal of 532. The calibration of the depolarization measurements was made by using the \pm 45 method, as proposed by [6].

\section{RESULTS}

\subsection{Measurement cases}

Two case studies from different days of observations are presented and discussed. These days showed almost persistent cirrus layers. Temperature observations used in the present study come from radio soundings, launched daily at 6 and 18 UTC at the Jyvaskyla Airport, located to the southwest of the lidar station.

The $16^{\text {th }}$ September case developed around 00:00 UTC and was observed for its entire lifetime until 04:30 UTC. This case has the cloud base average altitude around $9560 \mathrm{~m}$ and the cloud top average around 10964m (Fig. 1a). Lidar observations of backscatter and extinction coefficient profiles and depolarization ratio d are shown in Figure 1b,c,d. The mean Lidar Ratio was 30 sr and the cirrus optical depth was calculated 0.36. Temperatures between $-36^{\circ} \mathrm{C}$ (cloud base) and $-51^{\circ} \mathrm{C}$ (cloud top), confirm the that the cloud is mainly composed of ice crystals. In this case, a height dependent depolarization ratio is obvious (Fig. $1 d$ ). We can see a gradual decrease of the depol ratio inside cirrus layer, at heights between 10$11.5 \mathrm{~km}$. We can link this height dependence with variety of the ice particle size and orientation inside the layer.

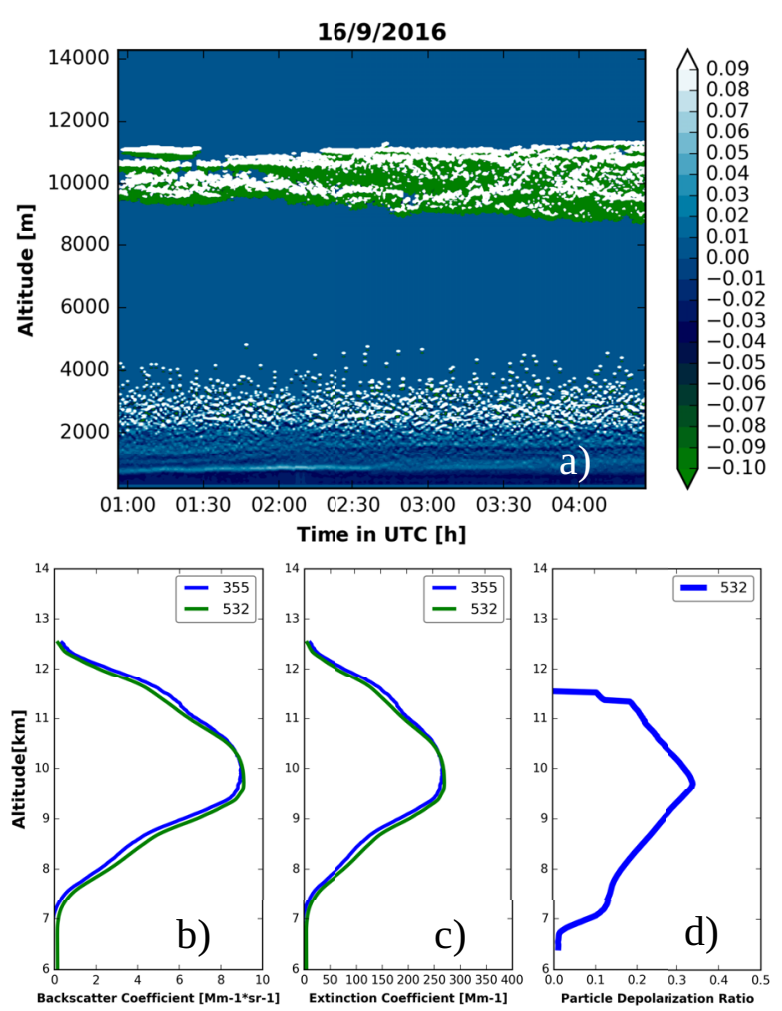

Figure 1: Cirrus cloud evolution observed at Kuopio on 16 September 2016 (a) and the calculated backscatter (b), extinction coefficient profile (c) and depolarization ratio (d).

The second case of the $20^{\text {th }}$ May is presented in Figure 2. For this case, the cloud base average altitude calculated $8800 \mathrm{~m}$ and cloud top average around $10334 \mathrm{~m}$. Lidar observations of backscatter and extinction coefficient profile and depolarization ratio $\delta$ are shown in Figure 2b,c,d. This case reveals that the depolarization ratio is almost constant inside the cirrus layer $(9-10.5 \mathrm{~km})$ and equal to 0.3 . The temperature values were equal to $-45.0^{\circ} \mathrm{C}$ and $-58.9^{\circ} \mathrm{C}$ for the cloud base and cloud top, corresponding to effective radius of 40 and $30 \mu \mathrm{m}$ accordingly [7]. The stability of the 
depolarization ratio could be linked to the stability of the temperature and as a consequence to the harmonised crystals shape inside the layer.

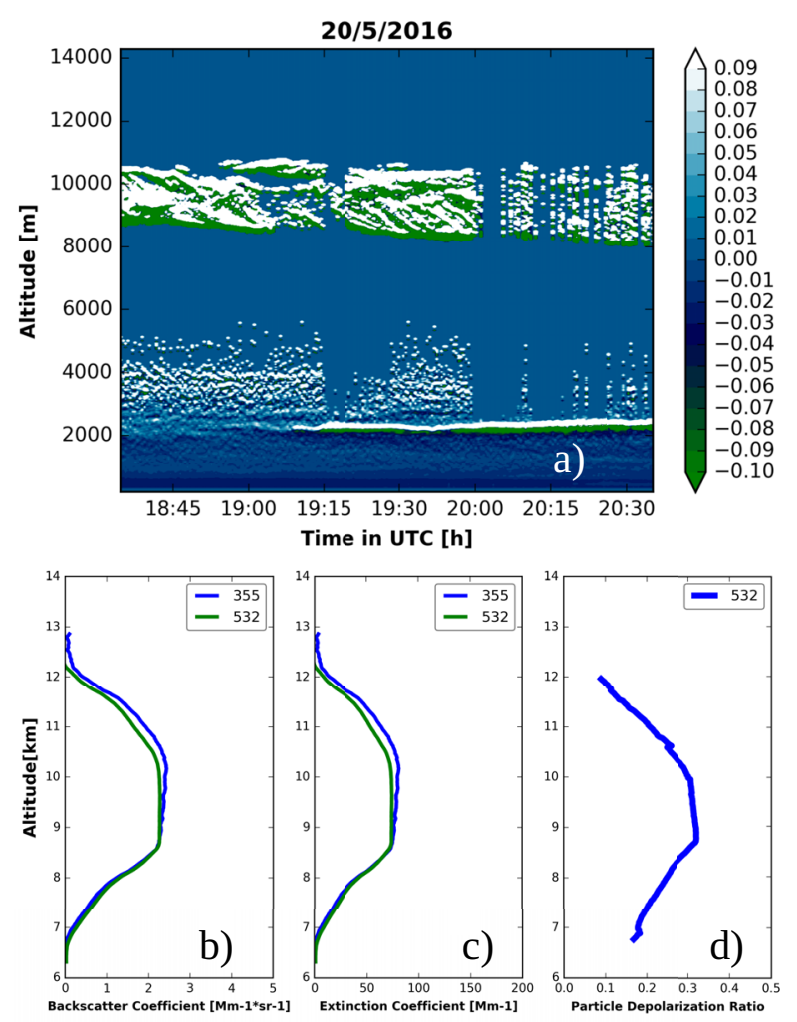

Figure 2: Cirrus cloud evolution observed at Kuopio on 20 May 2016 (a) and the calculated backscatter (b), extinction coefficient profile (c) and depolarization ratio (d).

\subsection{Results of the entire dataset}

The mean depolarization value was calculated for the whole period, with a large variability of observed values. Concerning the shape of crystals, higher depolarization values are linked to higher shape ratios (columns) and low depolarization values are linked to lower shape ratios (plates), according to literature [8]. A histogram of the occurrence of the depolarization values derived from our lidar dataset is presented in Figure 3. The figure shows that the most frequently observed depolarization values are found between 0.3 and 0.4 , corresponding to irregular crystall shapes.

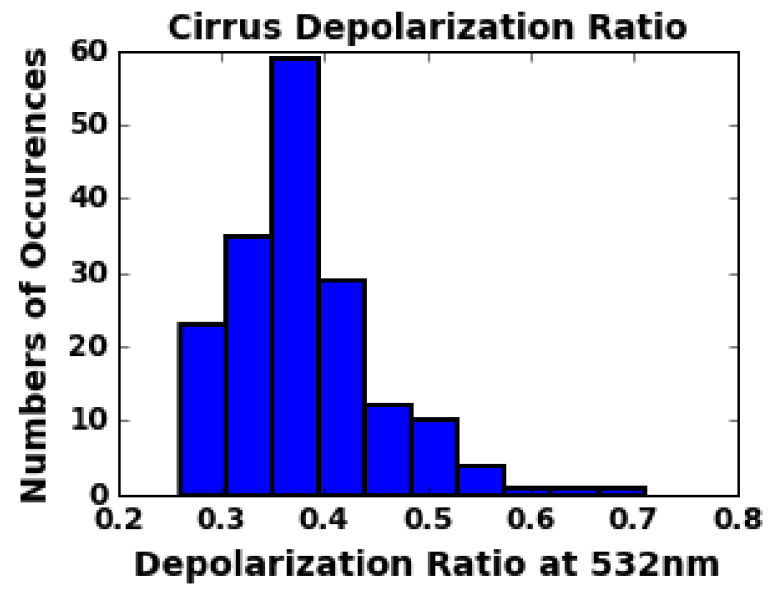

Figure 3: Depolarization ratio distribution of cirrus clouds.

In Fig. 4 we present the mean $\delta$ values in $5^{\circ} \mathrm{C}$ intervals of cirrus base temperature. The number of cases per temperature bin are also labeled. The error bars show the standard deviation of the observed mean depolarization values in each temperature interval. No clear tendency is found, as the variability of depolarization is relatively constant, with a slightly increase of the particle depolarization with the increasing mid temperature.

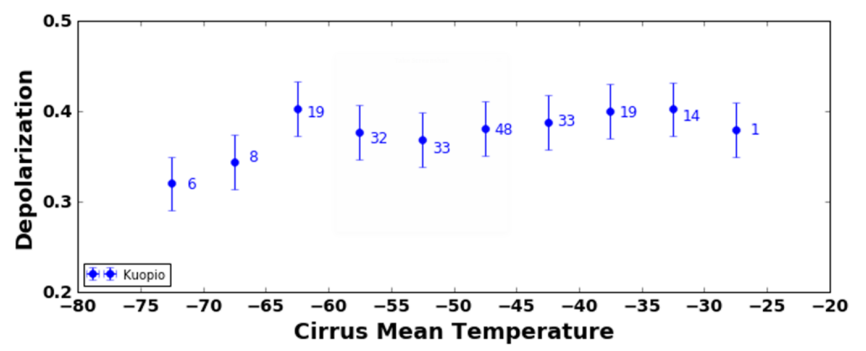

Figure 4: Mean $d$ values in $5^{\circ} \mathrm{C}$ temperature intervals. The number of cases per temperature bin are also labeled.

\section{CONCLUSIONS}

A dataset of mean depolarization ration values of cirrus clouds measured between 2012 and 2016 with a ground-based lidar was analyzed. The correlations with height, temperature and optical depth were also investigated and presented. 
In the future we intend to apply the investigation to a larger-scale climatological study in measurements from spaceborne instruments and examine the variation of ice crystals microphysical properties with geographical location. Furthermore, we aim to investigate the influence of the different ice crystal shapes to the radiative properties, so as to improve the ability to model the effects of cirrus clouds on climate.

\section{ACKNOWLEDGEMENTS}

We acknowledge support of this work by the project "PANhellenic infrastructure for Atmospheric Composition and climatE change" (MIS 5021516) which is implemented under the Action "Reinforcement of the Research and Innovation Infrastructure", funded by the Operational Programme "Competitiveness, Entrepreneurship and Innovation" (NSRF 20142020). Voudouri K.A acknowledges the support of the General Secretariat for Research and Technology (GSRT) and Hellenic Foundation for Research and Innovation (HFRI). (Scholarship Code: 95041).

\section{REFERENCES}

[1] Korolev, A. , Isaac, G. A. and Hallett, J., Ice particle habits in stratiform clouds. Q.J.R. Meteorol. Soc., 126: 2873-2902. doi:10.1002/qj.49712656913, 2000

[2] Noel, V., D. M. Winker, M. McGill, and P. Lawson, Classification of particle shapes from lidar depolarization ratio in convective ice clouds compared to in situ observations during CRYSTAL-FACE, J. Geophys. Res., 109, D24213, doi:10.1029/2004JD004883, 2004

[3] Stephens, G. L., S.-C. Tsay, P. W. Stackhouse, and P. J. Flatau, The relevance of the microphysical and radiative properties of cirrus clouds to climate and climate feedback, J. Atmos. Sci., 47, 1742 - 1753, 1990

[4] Engelmann R., Kanitz T., Baars H., Heese B., Althausen D., Skupin A., Wandinger U., Komppula M., Stachlewska IS, Amiridis V., Marinou E., Mattis I., Linne H., Ansmann A., 2015: EARLINET Raman lidar PollyXT: the next generation. Atmos Meas Tech Discuss 8:7737-7780. doi10.5194/amtd-8-7737-2015, 2015

[5] Baars, H., Ansmann, A., Engelmann, R., and Althausen, D.: Continuous monitoring of the boundarylayer top with lidar, Atmos. Chem. Phys., 8, 7281-
7296, https://doi.org/10.5194/acp-8-7281-2008, 2008. [6] Freudenthaler, V., Esselborn, M., Wiegner, M., Heese, B., Tesche, M., Ansmann, A., Muller, D., Althausen, D., Wirth, M., Andreas, F. I. X., Ehret, G., Knippertz, P., Toledano, C., Gasteiger, J., Garhammer, M., and Seefeldner, M.: Depolarization ratio profiling at several wavelengths in pure saharan dust during SAMUM 2006, Tellus B, 61, 165-179, 2009.

[7] Sassen, K. , P. W. Arnott, D. O.’ C. Starr, G. G. Mace, Z. Wang, and M. R. Poellot: Midlatitude cirrus clouds derived from Hurricane Nora: A case study with implications for ice crystal nucleation and shape. J. Atmos. Sci., 60, 873-891, 2003a.

[8] Korolev, A. , Isaac, G. A. and Hallett, J., Ice particle habits in stratiform clouds. Q.J.R. Meteorol. Soc., 126: 2873-2902. doi:10.1002/qj.49712656913, 2000. 